\title{
Standards for European Training Requirements in Interventional Neuroradiology
}

\author{
The European Multiplane Roadmap
}

\section{Gerhard Schroth ${ }^{1}$}

๑) Springer-Verlag GmbH Germany, part of Springer Nature 2020

The European Training Requirements in Interventional Neuroradiology were unanimously approved by the national representatives of the Neuroradiology Division of the Union of European Medical Specialists (UEMS) at the Assembly of Delegates on 2 March 2019 in Vienna and 1 day later by the delegates of the UEMS Section of Radiology. The Division of Neuroradiology was supported in the development of these guidelines by the UEMS Section of Radiology and the UEMS Division of Interventional Radiology, the European Society of Neuroradiology (ESNR) and the European Society for Minimally Invasive Neurological Therapy (ESMINT). The guidelines are based on and refer to the document "Standards of Practice in Interventional Neuroradiology, a consensus document from the ESNR/ESMINT/UEMS working group", which was adopted earlier.

After approval by the UEMS council in Brussels on 13 April, both documents were published on the website of the UEMS Division of Neuroradiology (https://neuro. uemsradiology.eu/) and were co-published in Neuroradiology [1] and the Journal of NeuroInterventional Surgery [2]. The UEMS website also contains links and documents describing the Union's organization, structure and objectives. In short, the scopes of UEMS include promoting the free movement of medical specialists, specialists in training and patients, harmonizing the highest level of specialist training and care, as well as defining standards in the field of postgraduate specialist training.

The Division of Neuroradiology was founded in an inaugural meeting on 13 September 2008 in Brussels as a sub-

Gerhard Schroth

gerhard.schroth@insel.ch

1 Univ. Institute for Diagnostic and Interventional Neuroradiology, University of Bern, Bern, Switzerland group of the Section of Radiology in addition to the Division of Interventional Radiology, which was established in 2009. Following old proven rules of the European federal structure, each Society of Neuroradiology of the currently 27 members of this division appoints its national delegates (in cooperation with the national medical authorities) who can vote at the biannual general meetings with one vote per country. Discussions about upcoming problems and the preparation of the delegate meetings and setting of the agenda take place via e-mail contact with and between the delegates and the members of the bureau, who are of course willing to receive comments and suggestions from anyone via the contacts given on the website.

It was a long journey until the above guidelines were adopted but good things take time, especially if they have to be worked out in the European federal structures in a transparent, open and goal-oriented manner.

When I started my training in interventional neuroradiology in Tübingen, Germany, in the mid-1980s, we learned the materials and skills directly on site from the pioneers, mainly in France and by attending small expert meetings such as in Val d'Isère, which is still a highlight for many of us in January every year. Through the direct exchange of expert knowledge, interventional neuroradiology was able to develop slowly and steadily without guidelines, respected in its niche, somewhat benevolently smiled at by neighboring disciplines and garnering public attention of the health sector.

This changed for the first time after our colleagues from England were able to prove that endovascular coiling of aneurysms is not only on par with neurosurgical clipping [3] but also superior in the long term [4], and when the vast majority of aneurysms became accessible to neuroendovascular image-guided microsurgery by improving materials and techniques. 
Interventional neuroradiology finally came into the spotlight when, 5 years ago, our Dutch colleagues showed with their pioneering MR CLEAN study [5] that endovascular treatment of ischemic stroke can lead to a dramatic improvement in clinical outcome, provided that planning, intervention and follow-up care are performed at a center with experience in interventional neuroradiology and treatment of stroke. This did not come as a surprise to the experts; on the contrary, we have to ask ourselves why it took so long for one of the most successful forms of treatment in medicine, with a number needed to treat below three, to become established.

With around 1.3 million acute strokes in Europe each year, of which at least 10-20\% can benefit from endovascular treatment, the urgent question arises as to where, how and by whom these patients can be optimally treated and how and where the experts in this field can be trained. Only few EU member states are prepared to keep up with this extremely high and fast-growing caseload for neuroendovascular treatment. At the same time, this also opens up new opportunities, especially for training and continuous education in our field of neuroradiology.

When the guidelines for training and practice in interventional neuroradiology were first proposed by the UEMS Division of Neuroradiology in 2011, diagnostic catheter angiography had just been replaced by the new techniques of CT- and MR-angiography (CTA and MRA), whereby the simplest and most logical first training step in becoming an interventional neuroradiologist had disappeared. The clinics for neuroradiology with usually 100-200 endovascular treatments for aneurysms and vascular malformations per year were faced with the problem whether a 24-h/365 day service should and could be established. Furthermore, how could colleagues be trained on these few and mostly complex cases?

With the breakthrough of endovascular stroke treatment, the new scientific facts answered many of these questions automatically. Time is brain means that diagnostic and interventional neuroradiology have to be available around the clock. This also implies that diagnostic and interventional neuroradiology should work closely together in a neurocenter where neurology, neurosurgery and anesthesia are available around the clock and where the interventional neuroradiologist in this network has access to the beds of the intensive and intermediate care and the stroke unit.

The two documents for training and practice in interventional neuroradiology define the human and technical resources to put this into practice. Following proven EU traditions, these recommendations are not intended to replace national regulations-some countries have already established even more advanced training curricula-but to serve as guidelines, for example, when negotiating the budget with the hospital administration. The scientific facts are that neuroendovascular treatment is not only effective in preventing disability but it also saves money, as recent publications have confirmed for stroke therapy [6,7]. This should help in discussions with health authorities when aiming to obtain adequate personnel, technical and financial means to build and run a high-quality diagnostic and interventional neuroradiology service of adequate size in relation to the catchment area. Reinvesting this money in education and quality of work makes sense, especially since the duration and cost of training to become an interventional neuroradiologist are considerable for the trainees, as is the strain associated with this work [8].

Based on the above considerations regarding the emergence of stroke in Europe, more than 500 emergency recanalizing stroke treatments per year must be calculated for a catchment area of 2 million people. In conjunction with the treatment of aneurysms and vascular malformations, this offers ideal conditions to train and teach knowledge and manual skills in interventional neuroradiology, especially since we know that often access can be more challenging than the endovascular, vaso-occlusive or vasoopening neurointervention itself.

From 2011 onwards, the first version of the training guidelines was adapted to these developments in an open, transparent and typically European federal principle. The delegates brought the ideas and wishes of their national societies to the delegates' meetings and discussed them with the members of the bureau of the division and section and invited representatives from ESNR and ESMINT. Thus, these documents, as published on our website, reflect and take into account regional differences and national peculiarities, which fortunately exist and will hopefully persist in Europe.

Conflict of interest G. Schroth is board member and Swiss delegate of the UEMS Division of Neuroradiology.

\section{References}

1. Sasiadek M, Kocer N, Szikora I, et al. Standards for European training requirements in interventional neuroradiology : Guidelines by the Division of Neuroradiology/Section of Radiology European Union of Medical Specialists (UEMS), in cooperation with the Division of Interventional Radiology/UEMS, the European Society of Neuroradiology (ESNR), and the European Society of Minimally Invasive Neurological Therapy (ESMINT). Neuroradiology. 2020;62:7-14

2. Sasiadek M, Kocer N, Szikora I, et al. Standards for European training requirements in interventional neuroradiology guidelines by the Division of Neuroradiology/Section of Radiology European Union of Medical Specialists (UEMS), in cooperation with the Division of Interventional Radiology/UEMS, the European Society of Neuroradiology (ESNR), and the European Society of Minimally Invasive Neurological Therapy (ESMINT). J Neurointerv Surg. 2020;12:326-31. 
3. Molyneux AJ, Kerr RS, Stratton I, for the International Subarachnoid Aneurysm Trial (ISAT) Collaborative Group International subarachnoid aneurysm trial (ISAT) of neurosurgical clipping versus endovascular coiling in 2143 patients with ruptured intracranial aneurysms: a randomised trial. Lancet. 2002;360:1267-74.

4. Molyneux AJ, Kerr RS, Birks J et al. Risk of recurrent subarachnoid haemorrhage, death, or dependence and standardised mortality ratios after clipping or coiling of an intracranial aneurysm in the International Subarachnoid Aneurysm Trial (ISAT): long-term follow-up. Lancet Neurol. 2009;8(5):427-33.

5. Berkhemer OA, Fransen PS, Beumer D, et al. A randomized trial of intraarterial treatment for acute ischemic stroke. N Engl J Med. 2015;372:11-20.
6. Kunz WG, Almekhlafi MA, Menon BK, et al. Public health and cost benefits of successful reperfusion after thrombectomy for stroke. HERMES collaborators. Stroke. 2020. https://doi.org/10. 1161/STROKEAHA.119.027874.

7. Mattle HP, Lindley RI. Mechanical thrombectomy saves costs after stroke due to large vessel occlusion. Stroke. 2020. https://doi.org/ 10.1161/STROKEAHA.119.028527.

8. Fargen KM, Arthur AS, Leslie-Mazwi T, et al. A survey of burnout and professional satisfaction among United States neurointerventionalists. J Neurointervent Surg. 2019;11:1100-4. 